\title{
Notas e descrições em Acanthoderini (Coleoptera, Cerambycidae, Lamiinae). II. Espécies novas do gênero Nesozineus
}

\author{
Maria Helena M. Galileo ${ }^{1,3}$ \& Ubirajara R. Martins ${ }^{2,3}$
}

\author{
${ }^{1}$ Museu de Ciências Naturais, Fundação Zoobotânica do Rio Grande do Sul. Caixa Postal 1188, 90001 -970 Porto Alegre, \\ Rio Grande do Sul, Brasil. \\ ${ }^{2}$ Museu de Zoologia, Universidade de São Paulo. Caixa Postal 42494, 04218-970 São Paulo, São Paulo, Brasil. \\ ${ }^{3}$ Pesquisador do CNPq.
}

\begin{abstract}
Notes and descriptions on Acanthoderini (Coleoptera, Cerambycidae, Lamiinae). II. New species of the genus Nesozineus. Four new species are described and figured in the genus Nesozineus Linsley $\&$ Chemsak, 1966: from Bolivia, N. puru sp. nov. (Santa Cruz), N. clarkei sp. nov. (Santa Cruz); from Panamá, N. giesberti sp. nov. (Coclé); from Peru, $N$. peruanus sp. nov. (Lima).

KEY WORDS. Neotropical; Nesozineus; taxonomy.
\end{abstract}

RESUMO. Quatro espécies novas do gênero Nesozineus Linsley \& Chemsak, 1966 são descritas e ilustradas: procedentes da Bolívia, N. puru sp. nov. (Santa Cruz), N. clarkei sp. nov. (Santa Cruz); do Panamá, N. giesberti sp. nov. (Coclé) e do Peru, N. peruanus (Lima).

PALAVRAS-CHAVE. Neotropical; Nesozineus; taxonomia.

O gênero Nesozineus foi estabelecido por LINSLEY \& CHEMSAK (1966) para única espécie, N. galapagoensis (Van Dyke, 1953). LANe (1977) descreveu Grossmannia para G. alphoides, porém Hoffmann (1984) sinonimizou-o com Nesozineus.

MARINONI \& MARTINS (1978) apresentaram chave para quatro espécies alocadas no gênero na época: N. bucki (Breuning, 1954) e $N$. juninensis (Lane, 1970), publicadas originalmente em Alphus White, 1855, N. galapagoensis e descreveram N. confusus do Espírito Santo.

Hoffmann (1984) publicou uma revisão do gênero quando $N$. confusus foi sinonimizado com $N$. alphoides e foram descritas cinco espécies: N. obscurus, procedente da Argentina; N. propinquus e $N$. fraterculus da Venezuela; $N$. bisignatus e $N$. griseolus ocorrentes no Brasil (Paraíba, Pernambuco e Bahia). O gênero ficou composto por nove espécies.

Galileo \& Martins (1996) publicaram uma chave para as 18 espécies, então contidas em Nesozineus, das quais nove foram descritas: N. ateuchus, N. marmoratus e N. apharus (Venezuela), N. zonatus (Brasil: São Paulo), N. lineolatus (Brasil: Mato Grosso do Sul), N. trivialis (Brasil: Minas Gerais ao Paraná, Mato Grosso do Sul e Goiás), N. armatus e N. granosus (Equador) e N. probolus (Peru). GALILEO \& MARTINs (2006) adicionaram Nesozineus simile procedente da Bolívia.

Descrevemos agora mais quatro espécies, uma delas do Panamá o que estende a distribuição de Nesozineus para a América Central que fica com 23 espécies.

As siglas mencionadas no texto correspondem a American
Coleoptera Museum (Coleção J. Wappes), San Antonio, Estados Unidos (ACMS); Museu de Ciências Naturais, Fundação Zoobotânica do Rio Grande do Sul, Porto Alegre, Brasil (MCNZ); Museo de Historia Natural Noel Kempff Mercado, Santa Cruz, Bolívia (MNKM); Museu de Zoologia, Universidade de São Paulo, Brasil (MZSP).

\section{Nesozineus peruanus sp. nov.}

\section{Fig. 1}

Tegumento acastanhado. Cabeça revestida por pubescência branco-amarelada. Vértice sem sensilas. Lobos oculares superiores com seis fileiras de omatídios; tão afastados entre si quanto pouco mais do que a largura de um lobo e unidos aos lobos inferiores por três fileiras de omatídios. Antenas atingem o ápice dos élitros na base do antenômero VII. Escapo revestido por pubescência esbranquiçada com pontos pequenos e contrastantes. Antenômeros III a XI revestidos por pubescência esbranquiçada; os antenômeros basais com pontos contrastantes.

Espinho lateral do protórax desenvolvido. Pronoto revestido por pubescência branco-amarelada, mais longa em duas áreas à frente do meio. Partes laterais do protórax cobertas por pubescência branco-amarelada entremeada por pontos contrastantes. Pronoto densamente pontuado; a pontuação encoberta pela pilosidade. Processo mesosternal tão largo quanto metade da mesocoxa. Metasterno revestido por pubescência esbranquiçada com pontos contrastantes nos lados. 
Pubescência elitral densa, predominantemente esbranquiçada, com áreas castanho-claras: no lado externo do terço anterior; junto à margem do meio ao ápice; no quarto apical que invade área próxima à sutura e vai até o meio na parte anterior da área apical, a pubescência é mais longa e situa-se sobre uma carena longitudinal, indistinta. Úmero ligeiramente projetado anteriormente Ápice elitral arredondado.

Fêmures recobertos por pubescência esbranquiçada e com pontos contrastantes. Tíbias com o mesmo tipo de pubescência dos fêmures, mas sem pontos contrastantes.

Dimensões, em milímetros, macho. Comprimento total, 10,7-10,8; comprimento do protórax, 1,8-1,8; maior largura do protórax, 3,2-3,3; comprimento do élitro, 8,3-8,5; largura umeral, 4,0-4,2.

Material-tipo. Holótipo macho e parátipo macho, Peru, Lima: La Molina, 22.X.1995, D. Rivera leg. (MZSP).

Discussão. Nesozineus peruanus sp. nov. assemelha se a Nesozineus galapagoensis variabilis Linsley \& Chemsak, 1966 que também é revestida por pubescência esbranquiçada com algumas manchas de pubescência acastanhada nos élitros; difere por apresentar o quarto apical dos élitros inteiramente coberto por pubescência acastanhada e pelo espinho nos lados do protórax mais longo. Em N. galapagoensis variabilis o quarto apical é revestido por pubescência acinzentada com pequenas manchas acastanhadas e o espinho nos lados do protórax é curto.

\section{Nesozineus puru sp. nov.}

\section{Fig. 2}

Etimologia. Tupi, purú = ornado, manchado; referente ao padrão do colorido elitral.

Tegumento castanho-escuro. Cabeça revestida por pubescência amarelada, densa. Vértice sem sensilas. Lobos oculares superiores com oito fileiras de omatídios, tão distantes entre si quanto a metade da largura de um lobo. Antenas atingem os ápices dos élitros na extremidade do antenômero VI. Antenômeros IV e V ligeiramente nodosos no ápice.

Protórax com espinho lateral manifesto; látero-posteriormente com duas sensilas de cada lado. Pronoto densamente pubescente; pontuação visível acobertada parcialmente pela densa pubescência.

Élitros cobertos predominantemente por pubescência esbranquiçada interrompida por áreas escuras: região basal, obliquamente do úmero até próximo da sutura, essa área envolve um ou dois pincéis de pêlos brancos; área central, mais ou menos transversal, de pubescência amarelo-acastanhada que envolve tufos esparsos de pubescência branca; terço apical, com duas fileiras longitudinais de manchas arredondadas, pretas. Úmero arredondado. Ápice elitral truncado em pequena extensão.

Fêmures e face ventral cobertos por densa pubescência branca. Extremidades das tíbias e tarsos pretos.

Dimensões, em milímetros, holótipo macho. Comprimento total, 8,5; comprimento do protórax, 1,6; maior largura do protórax, 2,6; comprimento do élitro, 5,9; largura umeral, 3,4.
Material-tipo. Holótipo macho, Bolívia, Santa Cruz: Cordillera (Puesto Salas), 19-21.III.2001, J. Ledezma \& W. Aliaga leg. (MNKM).

Discussão. Nesozineus puru sp. nov. assemelha-se a $N$. obscurus Hoffmann, 1984 conhecida da Argentina, mas difere, principalmente, pela coloração dos fêmures posteriores que são revestidos por pubescência branca, densa; as manchas pretas no terço apical dos élitros são organizadas em duas fileiras longitudinais. Em N. obscurus, os metafêmures são castanhos e as manchas escuras no terço apical dos élitros não são alinhadas.

\section{Nesozineus clarkei sp. nov. \\ Fig. 3}

Etimologia. Nome específico em homenagem a Robin Clarke, coletor do material-tipo.

Tegumento avermelhado. Cabeça, antenas, pronoto e fêmures revestidos por pubescência alaranjada. Vértice com alguns pontos. Antenas atingem o ápice dos élitros na base do antenômero VII (macho). Flagelômeros basais sem modificações. Lobos oculares superiores com cinco fileiras de omatídios, tão distantes entre si quanto pouco mais que a largura de um lobo.

Lados do protórax intumescidos no nível do meio e com espinho no terço posterior; uma sensila atrás de cada um dos espinhos. Pronoto fina e densamente pontuado.

Élitros com pubescência alaranjada; em cada um, duas faixas estreitas, paralelas de pubescência branca que se iniciam nos úmeros e se estendem até a sutura no quarto anterior; da faixa anterior até o terço apical, a sutura é ladeada de pubescência branca; no terço apical, faixa estreita, oblíqua em direção à margem de pubescência branca que, em alguns exemplares, desaparece completamente. Úmero arredondado. Ápice elitral arredondado.

Fêmures e face ventral cobertos por pubescência esbranquiçada. Lados do metasterno com pontos profundos.

Dimensões, em milímetros, respectivamente macho/fêmea. Comprimento total, 5,4-7,5/5,1-7,8; comprimento do protórax, 1,0-1,4/0,9-1,5; maior largura do protórax, 1,5-2,2/ 1,5-2,4; comprimento do élitro, 3,9-5,1/3,8-5,7; largura umeral, $1,8-2,9 / 1,8-2,9$

Material-tipo. BolíviA, Santa Cruz: Buena Vista $(4,6 \mathrm{~km}$ SSE, Hotel Flora \& Fauna, 450 m), holótipo macho e parátipo macho, 17-30.IV.2003, R. Clarke leg. (MNKM, MZSP); parátipo fêmea, 4-10.V.2003, R. Clarke leg. (ACMS); parátipo fêmea, 1520.XI.2003, R. Clarke leg. (MCNZ).

Discussão. O padrão de colorido dos élitros distingue $N$. clarkei sp. nov. das demais espécies do gênero.

\section{Nesozineus giesberti sp. nov. Fig. 4}

Etimologia. Nome específico em homenagem póstuma a Edmund F. Giesbert.

Cabeça, antenas e protórax com tegumento castanhoavermelhado. Fronte revestida por pubescência amarelada mo- 

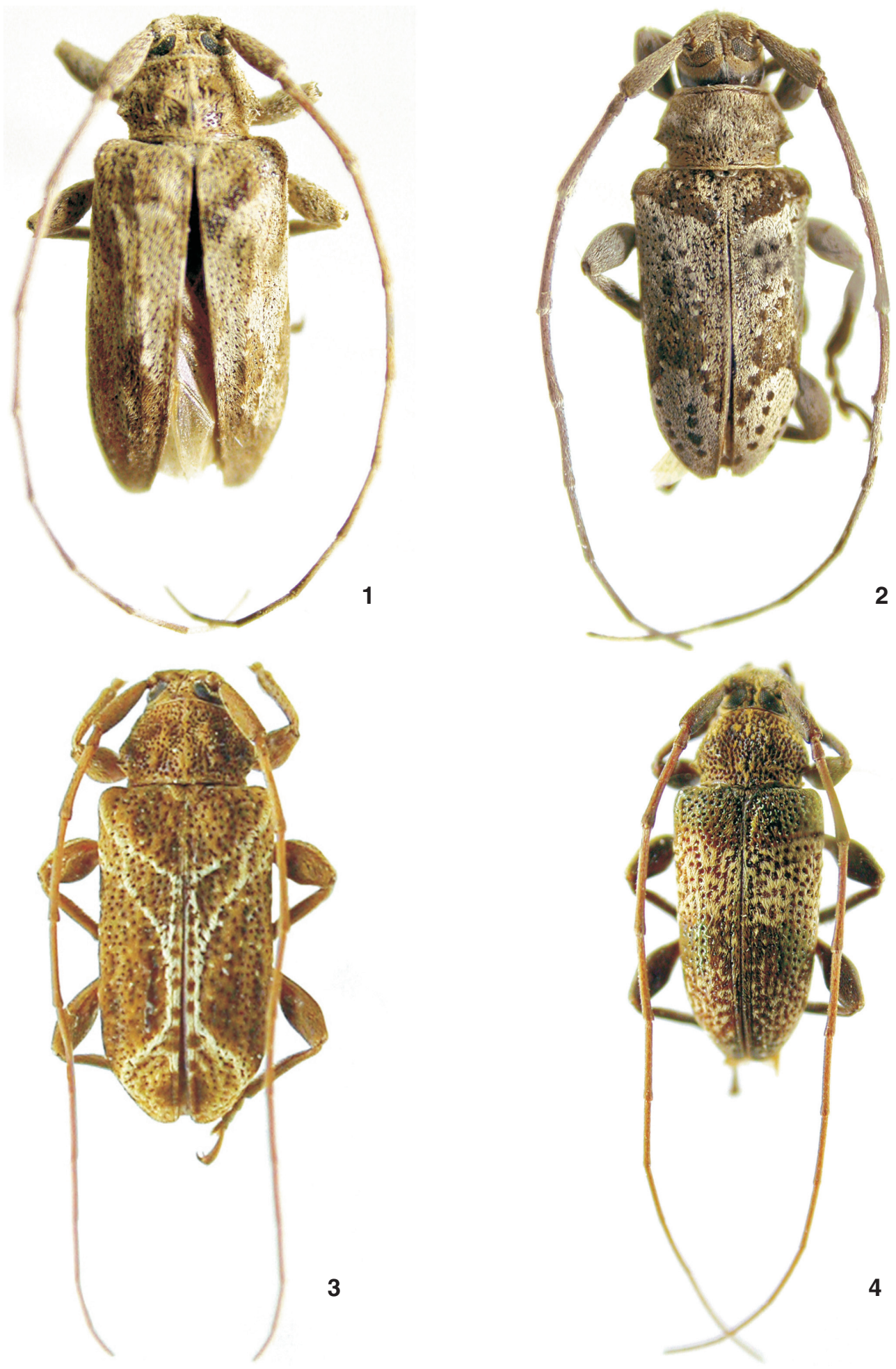

Figuras 1-4. Habitus. (1) Nesozineus peruanus sp. nov., holótipo macho, 10,7 mm; (2) Nesozineus puru sp. nov., holótipo macho, 8,5 mm; (3) Nesozinerus clarkei sp. nov., holótipo macho, 6,0 mm; (4) Nesozineus giesberti sp. nov., holótipo macho, 7,9mm. 
deradamente densa. Vértice, entre os tubérculos anteníferos e o occipício, com duas faixas estreitas de pubescência amarelada. Vértice sem sensilas. Lobos oculares superiores com sete fileiras de omatídios, mais próximos entre si do que a largura de um lobo. Três fileiras de omatídios na junção dos lobos superiores com os inferiores. Antenas atingem o ápice elitral no ápice do artículo VI. Escapo esparsamente pubescente. Base dos antenômeros IV e V com pubescência branca.

Protórax com o espinho lateral relativamente curto e uma sensila no lado posterior do espinho. Pronoto forte e densamente pontuado. Superfície entre os pontos com pubescência amarelada.

Élitros com duas faixas transversais de tegumento avermelhado com reflexos metálico-esverdeados: uma no quarto basal e outra depois do meio; uma faixa transversal de pubescência branca antes do meio, interrompida por numerosos pontos contrastantes; terço apical ocupado por pubescência branca entremeada por abundantes pontos contrastantes. Extremidades elitrais arredondadas.

Fêmures revestidos por pubescência branca, mais evidente na base. Tíbias com fileiras de grânulos no lado interno.

Face ventral coberta por pubescência branca, menos a parte látero-posterior do metasterno com pubescência densa mais amarelada.

Dimensões, em milímetros, macho. Comprimento total, 5,0-7,9; comprimento do protórax, 1,0-1,5; maior largura do protórax, 1,6-2,4; comprimento do élitro, 3,5-5,7; largura umeral, 1,8-2,9.

Material-tipo. Panamá, Coclé: El Valle (2400 pés), holótipo e parátipo machos, 16-22.V.1981, J. E. Wappes leg. (ACMS, MZSP).

Discussão. Nesozineus giesberti sp. nov. caracteriza-se pelo tegumento dos élitros com leve reflexo esverdeado-metálico e pelo padrão de colorido. Em N. apharus, conhecida da Venezuela, os élitros também não têm pubescência densa, mas em
N. giesberti sp. nov. a pubescência dos élitros é entremeada por pontuações contrastantes.

O padrão de colorido de $N$. giesberti sp. nov. poderia ser comparado com N. zonatus Galileo \& Martins, 1996, entretanto, $N$. zonatus só apresenta uma faixa de pubescência branca, transversal, e sem pontos contrastantes na metade anterior dos élitros e $N$. giesberti tem duas faixas transversais de pubescência branca entremeadas por numerosos pontos contrastantes.

\section{AGRADECIMENTOS}

A James Wappes pela remessa de material para exame (ACMS, MNKM); a Eleandro Moysés (MCNZ) pela execução das fotografias.

\section{REFERÊNCIAS BIBLIOGRÁFICAS}

Hoffmann, M. 1984. Nesozineus Linsley \& Chemsak, 1966 (Acanthoderini): sinonímias, descrições e chave para as espécies. Revista Brasileira de Entomologia 28 (4): 537-545.

Galileo, M.H.M. \& U.R. Martins. 1996. Revisão do gênero Nesozineus Linsley \& Chemsak, 1966 (Acanthoderini). Revista Brasileira de Entomologia 40 (1):41-46.

Galileo, M.H.M. \& U.R. Martins. 2006. Novos táxons em Hippopsini, Desmiphorini, Xenofreini e Acanthoderini (Coleoptera, Cerambycidae, Lamiinae). Papéis Avulsos de Zoologia 46 (3): 21-29.

LANE, F. 1977. Grossmannia alphoides, gen. n., sp. n. de Acanthoderini. Anais da Sociedade Entomológica do Brasil 6 (1): 3-6.

Linsley, E.G. \& J.A. Chemsak. 1966. Cerambycidae of the Galápagos Islands. Proceedings of the California Academy of Sciences (4) 33 (8): 197-236.

Marinoni, R.C. \& U.R. Martins. 1978. Notas sinonímicas e novas espécies em Acanthoderini (Coleoptera, Cerambycidae, Lamiinae). Papéis Avulsos de Zoologia 31: 173-193.

Recebido em 09.IV.2007; aceito em 27.VII.2007. 